\title{
Las exhibiciones etnológicas y coloniales decimonónicas y la Exposición de Filipinas de $1887^{1}$
}

\author{
LUIS ÁNGEL SÁNCHEZ GÓmEZ \\ Dpto. de Prehistoria y Etnología. \\ Universidad Complutense. Madrid
}

\section{RESUMEN}

Durante la segunda mitad del siglo xIx se celebran en Europa y América innumerables exposiciones etnológicas, coloniales y universales que materializan ante los visitantes la condición inferior y "salvaje" de las gentes colonizadas. Siguiendo de forma parcial esos modelos, se organiza en Madrid la Exposición de Filipinas de 1887. El objetivo del autor es presentar de forma global esa efervescencia expositiva y analizar la singularidad ideológica del evento madrileño.

Palabras clave: Colonialismo, Filipinas, Exposiciones universales, Exposiciones internacionales, Etnología.

\section{SUMMARY}

A large number of international, colonial and ethnological exhibitions were held in Europe and America during the second half of the nineteenth century, all of them designed to show visitors the inferior and "wild" nature of the colonized peoples. Partially in accordance with these precedents, the Philippine Exhibition was organized in Madrid in 1887. The author discusses in general terms such age of exhibitions and calls attention to the ideological singularity of the event held in Madrid.

Key words: Colonialism, The Philippines, World's Fairs, International Exhibitions, Ethnology.

La segunda mitad del siglo XIX y las dos primeras décadas del XX se dibujan como uno de los más destacados y triunfales periodos de la arro-

${ }^{1}$ Este artículo refunde el contenido de varios capítulos de un estudio del autor titulado Un imperio en la vitrina: el colonialismo español en el Pacífico y la Exposición de Filipinas de 1887, aún no publicado y financiado con cargo al Proyecto Complutense PR52/00-8912.

RDTP, LVII, 2 (2002): 79-104 
lladora y brutal expansión capitalista e imperialista de Occidente, y la exposición - universal, internacional, nacional o especializada- se convierte en el escenario más adecuado para dejar patente la inquebrantable fe en el supuesto "progreso de la humanidad" y para mostrar al mundo - y a las potencias rivales en especial- el desarrollo alcanzado por los estados organizadores y por todos aquellos invitados a participar en cada uno de los eventos. En este agitado contexto, la intensidad del fenómeno "exhibicionista" alcanza tales cotas que en algún escrito se compara a estos rituales de Occidente con los conocidos potlatches de las comunidades indígenas de la costa noroccidental de Norteamérica (Benedict 1983: 7). Esta misma autora remite igualmente al concepto de uritual de competición" que manejara Mauss, y termina calificando estos eventos como "orgies of competitive displays" (ibid.: 43). W. Plum (1977: 11) los define como "Santuarios de peregrinaciones hacia el fetiche mercancía" y añade otra observación importante: "las exposiciones mundiales satisfacían la necesidad social que sentía la burguesía europea, de poseer una comunicación internacional y una representación pública para compensar el predominio todavía vigente de la representación cortesana de la nobleza y las casas reales".

El formato exposición y más concretamente la denominada exposición internacional o universal -exposition universelle, world's fair, international exbibition, weltausstellung, wereld tentoonstelling...- es una creación esencialmente decimonónica ${ }^{2}$. Obviamente, desde tiempo atrás - y al margen de los gabinetes de curiosidades y de los museos- se documentan ferias, exposiciones de arte, muestras de productos, etc., en los que se presentan creaciones humanas o formas de la naturaleza interesantes o

\footnotetext{
${ }^{2}$ Aunque es ciertamente amplia la bibliografía disponible sobre exposiciones internacionales y universales, resultan muy recomendables las obras de carácter general de Greenhalgh (1988), Findling (1990), la reciente obra colectiva editada por Bancel et al. (2002) -volcada más hacia los "zoos humanos" que a las exposiciones universales propiamente dichas - y los varios libros escritos o editados por Rydell, algunos centrados en las exposiciones americanas y otros de alcance más general. De carácter eminentemente gráfico y divulgador es el texto de Calvo Teixeira (1992). Además, podemos citar artículos como los de Tenkotte (1987) o Corbey (1993), este último enfocado hacia el estudio de las exposiciones como ethnographic showcases. En las obras de Rydell, especialmente en la de 1992, se incluyen detallados repasos de la bibliografía disponible sobre las exposiciones universales; también en el trabajo conjunto de Rydell, Findling y Pelle (2000), aunque éste se centra en las exposiciones norteamericanas. Y, por supuesto, también se dispone de información en Internet. Simplemente tecleando términos como world's fair, international exbibition u otros semejantes en un buen buscador, como "google.com", se obtiene un extenso listado de páginas con información desigual.
} 
atrayentes por una u otra razón. Pero la exhibición especializada de productos y actividades con alcance supranacional, con un objetivo decididamente internacional e incluso mundial, es un fenómeno creado y desarrollado a partir de mediados del siglo XIX, aunque exista algún antecedente puntual en la centuria anterior, sobre todo en Gran Bretaña y Francia. Y esto es así al margen incluso de aceptar que la primera exposición universal sea precisamente la famosa "Gran Exposición de Trabajos Industriales de todas las Naciones" de Londres, que abre sus puertas en 1851, en el más famoso aún Crystal Palace. No obstante, si las exposiciones mundiales o universales se sitúan en la vorágine del modelo expositivo de la segunda mitad del XIX y primeras décadas del Xx, no faltan tampoco las internacionales especializadas e incluso las nacionales con afán de repercusión internacional, entre las que debemos situar precisamente la Exposición de Filipinas de 1887.

En la segunda mitad del siglo XIx, España no es ya más que una potencia colonial de muy segundo orden, pero aún conserva dos importantes territorios ultramarinos: las Antillas españolas y los archipiélagos del Pacífico (Filipinas, Marianas, Carolinas y Palaos). Es precisamente entonces, avanzada la penúltima década de la centuria y en medio de un episodio marcadamente expansionista del imperialismo occidental, cuando el débil imperio colonial español sufre la que resulta ser la más grave amenaza para su propia existencia en el Pacífico, al margen, por supuesto, de los hechos del período de 1896-98 que conducen a la independencia de Filipinas ${ }^{3}$. Nos referimos al conflicto hispano-alemán creado en torno a las islas Carolinas, larvado desde tiempo atrás y que estalla en agosto de 1885, resuelto con la mediación y arbitraje del Papa León XIII. Aunque el problema se solventó favorablemente para los intereses españoles, no sin ciertas concesiones, la administración hispana temía los afanes expansionistas de las potencias europeas en el Pacífico, que podían acabar afectando, de uno u otro modo, a Filipinas. Era necesario reforzar el dominio sobre los pequeños archipiélagos oceánicos, pero aún más perentoria resultaba la consolidación definitiva de la presencia colonial hispana en Filipinas. Y esto era así porque, aunque España administraba el citado archipiélago desde hacía más de tres siglos, factores tan determinantes como la lejanía de la metrópoli — sobre todo antes de la apertura del Canal de Suez-, su prácticamente nula colonización demográfica -nunca hubo en Filipinas más que algún que otro millar de españolesy la preponderancia de la administración religiosa —el clero regular espa-

${ }^{3}$ Habría que citar una segunda excepción: la ocupación británica de Manila en 1762. 
ñol- sobre la administración civil habían hecho de Filipinas una colonia, o "provincia de ultramar", ciertamente singular, bastante desconocida aún para los españoles y escasamente vinculada con la metrópoli.

Las circunstancias de carácter estructural apuntadas, unidas a otras muy diversas de índole coyuntural y al empeño personal de Víctor Balaguer político catalán que fue presidente del Consejo de Filipinas y ministro de Ultramar en aquellas fechas-, acaban dando el impulso definitivo a la idea de organizar en Madrid algún tipo de celebración que atraiga la atención sobre el archipiélago. Con la celebración de la Exposición de Filipinas de 1887, la administración española busca fomentar las relaciones económicas entre la metrópoli y el archipiélago y mostrar de modo general los rasgos fundamentales de aquellas lejanas tierras, desde su geografía hasta las formas de vida de sus muy variados grupos humanos. En último término, la pretensión es consolidar y de algún modo modernizar la presencia colonial en el archipiélago. Para lograrlo, se muestran en Madrid, en el Parque del Retiro, productos de todo tipo - especialmente agrícolas-, manufacturas tradicionales, ejemplares de la fauna y de la flora, numerosísimos útiles y artefactos de carácter etnográfico - tanto de pueblos cristianos como "salvajes" - y, lo que resulta mucho más impactante, se levanta en el recinto de la exposición un conjunto de edificios que reproduce las viviendas tradicionales - nuevamente de pueblos cristianos y de "Salvajes" - de las islas, en las que desarrolla sus actividades artesanales o meramente vitales un nutrido grupo de filipinos, entre los que se encuentra una amplia representación de igorrotes $^{4}$ y moros $^{5}$,

\footnotetext{
${ }^{4}$ El término igorrote fue utilizado por los españoles para nombrar a un buen número de pueblos salvajes de las montañas de Luzón, ya que, al parecer, las gentes de las tierras bajas vecinas denominaban a aquéllos igolot, esto es, gente de la montaña, dado que golot es un término del tagalo antiguo que significa sierra o cordillera (Scott 1988: xiii). Aunque todavía puede encontrarse en alguna obra etnográfica contemporánea, lo cierto es que la denominación genérica de igorrotes fue desterrada desde hace algunas décadas de la bibliografía antropológica. Pero la cuestión terminológica se complica, o quizás se aclara, aún más por el hecho de que desde hace algunas décadas el término igorot viene siendo reivindicado por algunos grupos étnicos de las montañas de Luzón para articular su identidad cultural, como hicieron antes los musulmanes con el calificativo de moro. Así, igorrotes emigrantes en Estados Unidos han creado una Igorot Global Organization e incluso editan una publicación periódica con el título de Igorot Quarterly (Afable 1998).

${ }^{5}$ El término moro lo aplicaron los españoles a los pueblos malayos de religión musulmana con los que, literalmente, se toparon en Filipinas en el siglo Xvi. Aunque en un principio tuvo, indudablemente, un carácter peyorativo, semejante al que de hecho ofrecía en la Península, con el paso del tiempo se convirtió en la denominación utilizada de forma general para nombrar a los filipinos malayos pertenecientes al
} 
además de sendos carolinos, dos chamorros de Marianas y un $n e-$ grito $^{6}$.

Pero antes de continuar identificando los rasgos definidores de la muestra del 87, es necesario analizar aquello que la separa de exhibiciones contemporáneas aparentemente similares. En este sentido, consideramos que existen diferencias sensibles entre el modelo de 1887 y las exposiciones "etnológicas" o "etnográficas" de carácter lúdico-comercial o pseudocientífico-comercial que proliferan por toda Europa y los Estados Unidos desde mediados del XIX hasta los años 30 del Xx. Durante ese largo periodo de tiempo, y cada pocos meses, se presentan en público grupos más o menos numerosos de individuos procedentes de lejanos y exóticos territorios a quienes, supuestamente, se quiere dar a conocer al público y poner a disposición de antropólogos y estudiosos de toda condición. El carácter circense y denigrante de estos eventos es más que obvio; no en vano las exhibiciones se celebran en numerosas ocasiones en circos, en los tristemente famosos "jardines de aclimatación" o, directamente, en parques zoológicos (Bancel et al. 2002). Así, los salvajes humanos comparten espacio físico y simbólico con las fieras salvajes, ya que para la sociedad del momento ambas comunidades de seres vivos participan de una casi idéntica esencia animal.

Esas exhibiciones no son algo exclusivo del ochocientos. Sabemos que al menos desde el siglo XV se presentan en Europa seres humanos considerados salvajes, extraños o primitivos, aunque es cierto que entonces son mucho más comunes, sobre todo durante el siglo XvIII y la primera mitad del XIX, las exhibiciones circenses o pseudocientíficas de monstruosidades humanas y animales (Bodgan 1988). Pero desde mediados de esta última centuria el fenómeno se dispara, al tiempo que se transforma. A partir de los años $70 \mathrm{y}$, sobre todo, de los 80 , se produce una reorientación gradual de lo simplemente raro, curioso o monstruoso a lo exótico, salvaje o primitivo (Feest 1987; Benedict 1994; Mason 1998a, 1998b). Las exhibi-

Islam. Incluso los propios musulmanes lo hicieron suyo, a modo de rasgo de identidad. Véase en este sentido la proliferación del término moro en organizaciones de todo tipo, incluidas las políticas de carácter independentista, como puede ser el Moro National Liberation Front, que pretende la independencia de la comunidad Bangsa Moro - literalmente, "nación o pueblo moro"-, esto es, de la población mora y los territorios de Sulú (archipiélago de Joló), Mindanao, Basilan y Palawan (Paragua).

${ }^{6}$ Negrito fue la denominación que los españoles aplicaron a los individuos de piel negra y baja estatura que encontraron en el Filipinas, nombre que ha sido asumido de forma generalizada en el ámbito de la antropología. Se les conoce también como aeta, ita, agta y otras diversas denominaciones locales. Su hábitat se localiza mayoritariamente en áreas montañosas y aisladas de Luzón, Visayas y Mindanao. 
ciones tienen a partir de entonces un carácter más marcadamente exotista y colonial que estrictamente singular, aunque no por ello se abandonan los freak shows. Si en esos renovados contextos feriales el individuo exhibido continúa siendo una atracción en sí mismo, lo es aún más y de manera especial por el hecho de representar a gentes, a grupos, a pueblos enteros cuyas condiciones materiales de supervivencia, cuyas creencias y desconocidos rituales resultan tan incomprensibles como excitantes, tan llamativos como repugnantes, para los civilizados ciudadanos de la sociedad occidental. $Y$ esto ocurre tanto en las exhibiciones estrictamente comerciales, como en las que se celebran formando parte de una exposición universal, en las conocidas "villas negras", como seguidamente comprobaremos. Por supuesto, estos eventos no nos ofrecen apenas ninguna información etnográfica o antropológica sobre las gentes exhibidas, no es ése el interés que pueden tener hoy para la comunidad científica; su valor reside en que son un "extraordinario instrumento de análisis de las mentalidades [occidentales] desde finales del siglo XIX hasta los años 30 [del XX]" (Bancel, Blanchard y Lemaire 2000).

La brutalidad que caracteriza a la mayoría de estas exhibiciones - incluidas las de finales del $\mathrm{xIX}$ y principios del $\mathrm{xx}$ - es casi inimaginable. Sus artífices, los "empresarios", recurren en numerosas ocasiones a la simple captura, al rapto de los indígenas, a quienes trasladan y exhiben de forma incansable de uno a otro lugar, con el beneplácito, salvo alguna que otra excepción, de las autoridades, del público, de las instituciones científicas y de gran parte de los más prestigiosos antropólogos y naturalistas de la época (Mason 2001; Bancel et al. 2002). Aunque la coacción, con mayor o menor intensidad, debió de ser el recurso más utilizado para conseguir la participación de los nativos en estas exhibiciones, en alguna ocasión encontramos documentados mecanismos más cínicos y sutiles, si en realidad esto fuera posible. Así, en 1885, en Amberes, se consiguió -si aceptamos la veracidad de las crónicas de la época- que el jefe de un grupo de doce "negros congoleños" llegados para su exhibición aceptara su participación en el espectáculo asegurándole que no era él quien iba a ser exhibido, sino que serían precisamente los ciudadanos belgas quienes pasarían frente a su "residencia" en el jardín de aclimatación para ser contemplados por su augusta persona (Coutancier 1992: 38).

España no es ajena a estos eventos, si bien es verdad que el fenómeno expositivo especializado no alcanza aquí las cotas que en otros países europeos. Al margen de los muy numerosos espectáculos feriales y circenses que sin duda debieron de celebrarse, conocemos al menos dos exhibiciones "etnográficas" de pueblos primitivos, ambas posteriores a la muestra filipina. Efectivamente, en 1897 se presenta, primero en Barcelo- 
na, más tarde en Madrid y puede que en alguna otra ciudad, un numeroso grupo de individuos de etnia ashanti procedentes del África Occidental británica. Su periplo europeo era estrictamente comercial y estaba organizado por un empresario de nombre M. Gravier (Contreras y Terrades 1984).

Similar objetivo crematístico era el perseguido con la denominada "primera exhibición en Europa de una aldea esquimal", que recala en Madrid en marzo de 1900 como parte de una amplia gira europea (Cabrera Latorre 1900; Verde Casanova 1993, 1994) ${ }^{7}$. Por supuesto, en ambos casos los individuos exhibidos desarrollan todo tipo de tareas más o menos tradicionales en estructuras habitables también originales; lo que, obviamente, genera un enorme interés en el público y atrae a las muestras a cientos e incluso miles de personas, cada una de las cuales deja en taquilla la peseta que cuesta el acceso al recinto, lo que supone unos importantes beneficios económicos para los organizadores. En ambos casos, y pese a que existe un trasfondo informativo y pseudocientífico, los fines son pura y exclusivamente mercantiles; no se trata de iniciativas oficiales y las personas que en ellos participan ni son invitados de los organizadores - como teóricamente lo fueron los filipinos de 1887- ni tienen otra condición, en el mejor de los casos, que la de simples asalariados, aunque el modelo expositivo del que forman parte les acerca más a la condición de seres raros que a la de trabajadores.

Si en las exposiciones citadas, incluidas las vistas en España, las actividades cotidianas más o menos singulares desarrolladas por los personajes exhibidos son un complemento al exotismo de la propia imagen externa de los individuos, en otros eventos el espectáculo, entendido en su más moderna acepción, se sitúa cuanto menos a un mismo nivel de importancia que el exotismo de sus protagonistas. Esta modalidad de exhibición eminentemente espectacular es cien por cien made in America, y llega a Europa con el famoso Buffalo Bill's Wild West Show, dirigido por este conocido personaje del "Salvaje Oeste" americano. Su primer tour

\footnotetext{
7 A. Verde no menciona un interesante folleto de 1900 que se conserva en la biblioteca del Museo Nacional de Antropología de Madrid (sede de Alfonso XII), que lleva por título Los habitantes del Polo Ártico en los Jardines del Buen Retiro de Madrid: primera exhibición en Europa de una aldea esquimal (Madrid: R. Velasco, impresor, 1900), en el que se describen de forma breve pero bastante sensata los rasgos físicos y culturales de estas gentes. Por cierto, que el folleto incluye unas hojas con anotaciones manuscritas sobre los precios de los productos que podían adquirirse durante la exhibición y una relación completa de los esquimales - veintidós, más una niña de seis años-, los perros que les acompañaban - trece- y el nombre de los dos "dueños" - así se anota- de la colonia, Ralph G. Taber y su esposa, a quienes se suma un tal Arthur Taber, que puede ser un hijo.
} 
europeo se inicia en Gran Bretaña en 1887-88 y se repite en 1889-1892 y 1902-1906, recalando con sus giras en un buen número de países, incluida España.

La Exposición de Filipinas, si bien saca provecho de toda esta moda exhibidora de pueblos salvajes e incluso alcanza a diseñar un programa de espectáculos indígenas, tiene como modelo de referencia inmediato, más bien como inspiración, a la exposición universal, no a la mera exhibición lúdico-comercial-primitivista. Pero no nos referimos a la exposición universal de edificio único y orientación casi exclusivamente mercantil e industrial, como fue la de Londres de 1851, sino a la que se materializa a partir de la segunda exposición celebrada en París, la de 1867, que abre sus puertas a la diversión y la "educación" a través de la vía exotista. Pese a lo dicho, la comparación que hacemos entre la exposición de 1887 y las universales de la época debe valorarse en su justa medida. Ni los objetivos ni las dimensiones de una y otras son equiparables. Lo que sí se puede comparar es el modelo en su diseño básico, aunque aparezca muy recortado y especializado en el caso madrileño.

En efecto, una de las características más singulares de casi todas las exposiciones universales, que explota con entusiasmo el certamen filipino de 1887, es la presentación - junto con el arte, la industria y el estado de desarrollo económico, social y cultural global de cada país participante- de elementos de la "cultura tradicional" de las comunidades que los habitan y de los territorios coloniales de las potencias occidentales que organizan tales eventos. En pocos años se da el salto desde las maquetas y los escasos objetos de carácter más o menos etnográfico vistos en la exposición de 1851, hasta la construcción de edificios y barrios enteros que reproducen lugares "típicos" de determinados países o colonias. Esto ocurre por vez primera en París, en 1867, donde además del pabellón expositivo central se levantan algunos pabellones nacionales y otros edificios que tienen como principal objetivo atraer la atención de los visitantes mediante reconstrucciones arquitectónicas y la presentación de productos y objetos llegados de países y territorios más o menos exóticos, en la mayoría de las ocasiones mostrados, expendidos o fabricados por individuos oriundos de aquellas tierras. La aldea tirolesa, el caravansar oriental, los baños turcos, las mezquitas y barrios musulmanes, todos ellos vistos en París en 1867, se convierten desde entonces en elementos absolutamente imprescindibles en casi todas las exposiciones universales. Es necesario señalar, no obstante, que todas estas atracciones tienen en estas iniciales exposiciones un eminente carácter ferial - severamente criticado por algunos personajes en la época-, y que será en los certámenes inmediatamente posteriores cuando aparezcan los primeros espacios o pa- 
bellones oficiales que se habrán de convertir en auténticos y fenomenales vehículos de construcción simbólica y material del ámbito colonial, lo que no impide que en la mayoría de estas ferias continúen levantándose de forma paralela contextos expositivos exotistas estrictamente lúdicos.

En todo caso, la aparición de estructuras habitables nativas - ya estén concebidas como simple atracción ferial con objetivos exclusivamente crematísticos o como "escuela colonial - hace necesaria la presencia viva de las gentes que originalmente las habitan, ya se trate de aldeas tirolesas, españolas, irlandesas, griegas o turcas, de poblados pigmeos o de comunidades esquimales. De este modo, se une el folklorismo doméstico y el exotismo de los países orientales - y de algunos europeos- con la exhibición propiamente etnológica y antropológica de las gentes que pueblan las colonias. Con ello se combina, al menos en teoría, la propuesta lúdica con la finalidad científica y educativa. Así, el público europeo y americano, la opinión pública en general, puede conocer tanto a sus "hermanos" o, mejor, a sus "salvajes" de allende los mares, como a los habitantes en principio civilizados de otros países o, incluso, de sus propias naciones; puede gozar, en resumen, de una auténtica fantasía visual: recorrer el mundo - un mundo virtual y selecto- en sólo unas horas. A la vez, los científicos disponen de "ejemplares vivos", sobre todo en relación con los pueblos primitivos, para hacer avanzar los estudios etnológicos y antropológicos, lo que en muchos casos se traduce, simple y llanamente, en la articulación y justificación de modelos de interpretación racista de la humanidad. Por supuesto, insistimos en ello, en casi todas las exposiciones se organizan espacios y estrategias diferentes de exhibición según se trate de mostrar a seres primitivos o salvajes, procedentes de las colonias, o a gentes llegadas de territorios más o menos exóticos de Europa o de Asia, la mayoría procedentes de estados soberanos. En este sentido, los argumentos que expresan públicamente los responsables, con el objeto de justificar la exhibición de los habitantes de las colonias son siempre los mismos: todo se hace con el doble y muy loable propósito de presentar en sociedad a las gentes colonizadas y de mostrarles y demostrarles de modo tangible e inapelable la riqueza, la potencia y la superioridad material y moral de la metrópoli, lo que supuestamente redundaría en un acatamiento sin fisuras de la autoridad colonial. Sea como fuere, no debemos olvidar que estas exhibiciones humanas "oficiales", ya se celebren de forma individualizada o formando parte de una exposición universal, aunque apuntan hacia determinados objetivos educativos o informativos, acaban participando de muchas de las características más negativas y denigrantes, propias de las exhibiciones particulares de estricto carácter mercantil que citáramos párrafos atrás, circunstancia que se 
hace especialmente notoria cuando la administración deja en manos de concesionarios o empresarios privados la organización y explotación del evento expositivo, algo que, como veremos, no ocurre en Madrid en 1887.

Estas exhibiciones de carácter colonial apenas si provocan reacciones de protesta por la exhibición de seres humanos y por el propio entramado de explotación que sustentan y legitiman. Podemos ir incluso más lejos y asegurar que no pocos de estos certámenes, sobre todo aquellos que fueron diseñados de forma más inteligente y exitosamente manipuladora, sirvieron justamente para presentar al público - $\mathrm{e}$ instalar en sus mentes- unas imágenes no sólo falsas sino totalmente opuestas a la realidad del hecho colonial.

En este sentido, quizás sean las exposiciones universales belgas de fines del xIx y comienzos del xx la mejor muestra de lo que decimos. A ellas se debe en una medida nada despreciable, sobre todo a la exposición de Bruselas de 1897, que el genocida régimen de gobierno instaurado por Leopoldo II, el rey de los belgas, en su particular Estado Independiente del Congo se trastocara a los ojos del público en una excelsa misión filantrópica, aunque es cierto que este singular personaje venía "trabajando" esa imagen de estadista humanitario desde mucho tiempo atrás. Y no pensemos que se trata de imágenes o mensajes caducos, propios de un lejano pasado: el catálogo de una reciente exposición belga, que precisamente recrea la Belle Europe del tiempo de las exposiciones universales (entre 1851 y 1913), repasa la parcela colonial de las universales belgas de modo harto complaciente y lisonjero, e incluso describe a Leopoldo II como "una curiosa mezcla de filantropía sincera y espíritu de lucro", sin más aclaraciones sobre su sanguinaria empresa africana (Belle Europe 2001: 113). Y todo ello pese a que ya desde fines del XIX se publican contundentes escritos de denuncia y a pesar, también, de la relativamente abundante bibliografía que desde entonces desvela la tétrica y esquilmadora práctica colonial del monarca belga, entre la que podemos citar el trabajo de Hochschild (2002), que precisamente acaba de ser editado en español.

Pero retornemos a nuestro hilo argumental central. Todo este despliegue de habitantes de las colonias - - , insistimos, de ciertos países exóticos, incluidos algunos europeos- que estamos revisando, la "muestra viva" de sus gentes y no la simple exhibición etnográfica de objetos, aparece por vez primera en la ya citada exposición de París de 1867 y, con algo más de intensidad, en Filadelfia, en 1876, y nuevamente en París, en 1878. Sin embargo, en estas tres exposiciones aún no se "exhibe" propiamente a indígenas, ya que éstos participan teóricamente como responsables de la venta de productos exóticos en los muy populares restaurantes étnicos 
o desarrollan, de forma más o menos evidente y necesaria, alguna que otra actividad, lo que no impide que de forma paralela a los certámenes se organicen algunas exhibiciones "etnográficas", como la de unos pretendidos "hombres salvajes de Borneo" vistos en las inmediaciones de la exposición de Filadelfia del 76.

Pero es en París - siempre París- en 1878, cuando ese recurso ferial exotista alcanza unas insospechadas cotas de éxito y favor popular - hasta el punto de consolidar el modelo en las futuras muestras-, gracias a la creación de la desde entonces archifamosa "Rue des Nations", la "Calle de las Naciones", que da cabida a la no menos exitosa y aún más exótica "Calle del Cairo". La exhibición desaforada y casi circense de seres humanos va a ser patrimonio de los eventos feriales inmediatamente posteriores, circunstancia que sin duda tiene mucho que ver con los avances de la moderna ciencia antropológica, como recuerda Greenhalgh (1988: 86), $y$, por supuesto, con la intensificación de la expansión colonial europea en África tras la celebración de la Conferencia de Berlín de 1884-85. Este nuevo modelo, aunque reproduce igualmente la "Calle de las Naciones", añade a la estructura expositiva nuevas secciones - las que se van a conocer como "villas negras" o "villas indígenas" - con un talante y una ideología marcadamente más colonialistas, racistas y social-darwinistas, viéndose consolidado ya a partir de la "Exposición Internacional Colonial y de Exportación General" de Amsterdam, celebrada en 1883, si bien alcanza su máximo apogeo nuevamente en París, en las exposiciones universales de 1889 y 1900 , y en la colonial internacional de 1931, además de en las coloniales nacionales de Marsella, de 1906 y 1922, y en la World's Fair de San Luis de 1904. Con todo, no se quedan muy a la zaga las ya mencionadas secciones coloniales de las exposiciones universales belgas de fines del XIX y comienzos del Xx y las coloniales británicas celebradas durante ese mismo periodo. Pero es Amsterdam el referente más inmediato en el que se inspira, si bien de forma parcial y con un trasfondo ideológico claramente diferenciado, la Exposición de Filipinas de 1887. Conviene hacer, por tanto, algunas observaciones sobre el certamen neerlandés.

La exposición de Amsterdam de 1883 no es la única especializada en el ámbito colonial que se celebra en Europa durante aquellos años de apogeo expositivo, pero sí la más importante ${ }^{8}$. Se organiza en tres sec-

${ }^{8}$ Tres años después, en 1886, se celebra en Londres la exitosa Colonial and Indian Exbibiton, a la que siguen otras muchas durante más de medio siglo. En realidad, la exposición de Amsterdam no fue única y exclusivamente colonial, como sí fue el caso de la de Londres. Las citas referidas a la organización del certamen neerlandés se toman del folleto Exposición Colonial (1882). 
ciones principales: "exposición colonial", "exposición de artículos de exportación general para las colonias y las posesiones de Ultramar" y "obras modernas", esto es, bellas artes. Obviamente, esta última sección responde a algo que resulta muy del gusto de la época y que se convierte no sólo en un reclamo para el público, sea cual fuere el contexto expositivo, sino en un referente que articula la identidad y el prestigio del país organizador. Por la información disponible, parece que tuvo escasa vinculación directa con los restantes contenidos de la muestra.

Aunque la sección segunda de esta exposición tiene un notorio interés historiográfico, ya que nos informa sobre todos aquellos sectores de la actividad económico-productiva que se pretendían orientar hacia el mercado colonial, es evidente que la primera, la "exposición colonial" propiamente dicha, se presenta como el eje central del certamen. Resulta muy ilustrativo comprobar las semejanzas y diferencias existentes entre el programa de esta sección y su equivalente en la de Madrid de 1887.

En Amsterdam, esta primera parte se organiza en tres grupos. El primero se orienta hacia el estudio de "La naturaleza de las comarcas conquistadas y colonizadas" y se estructura en siete apartados sobre geografía, meteorología, configuración del terreno, geología, flora, fauna y antropología. La sección primera de la exposición de 1887 coincide exactamente con la holandesa, aunque destaca el hecho de que en Madrid se reserva una específica para la flora y la fauna. Pero mucho más llamativos son los otros dos apartados de esa primera sección de Amsterdam. El segundo lleva por título "La población indígena de estas comarcas" - se refiere, obviamente, a las colonias-, haciéndose expresamente, a renglón seguido, la siguiente aclaración: "Con exclusión de los habitantes de origen o pertenecientes a las razas europeas". Y esto es así porque el tercer grupo se dedica precisamente a "Los europeos en aquellas comarcas y sus relaciones con los indígenas". Los contenidos de ambos grupos aparecen descritos con todo pormenor en el programa, configurando el primero de ellos una completa guía para el estudio etnográfico de las poblaciones indígenas colonizadas y el segundo un detallado repaso a los sistemas coloniales y a la organización social de los europeos en aquellos territorios.

Esta drástica dicotomía entre población europea y población indígena, entre instituciones y modos de vida de unos y otros, entre colonizadores y colonizados, en definitiva, es algo que no se documenta en la exposición de Madrid. Es obvio, no obstante, que esta última muestra establece en la práctica una cierta diferenciación entre los planos estrictamente indígenas - ya sean cristianos, musulmanes o paganos-y los contextos de la sociedad colonial de origen español o, sencillamente, occidental. Resul- 
ta obvio, por ejemplo, que entre los individuos "exhibidos" no hay representantes -y podría haberlos habido, como apuntó con ironía alguna crítica de prensa de la época- de la clase rectora, de los españoles que detentan la mayor parte de las responsabilidades en la economía, la administración y el gobierno de las islas. También se podría afirmar, como igualmente se hizo, que sí hubo una "exhibición" parcial de europeos, aunque en realidad lo que se expusieran fueran las creaciones de algunos de estos personajes. En cualquier caso, es evidente que en Madrid se agrupan y reúnen bajo un mismo epígrafe y en un mismo espacio expositivo todas las creaciones humanas, indígenas o europeas, que pertenecen a un mismo área de referencia funcional: agricultura, comercio, actividades industriales, vida social, arte, etc.

Un ámbito más en el que se singulariza la exposición de 1887 con respecto a otras de la época, incluida seguramente la de Amsterdam, es en el modelo de relaciones establecido con los indígenas "exhibidos". Pero no se trata de valorar en este momento las circunstancias de su residencia en la Península y las condiciones higiénico-sanitarias de las estancias que habitan. En realidad, por los datos disponibles sabemos de la existencia de graves deficiencias en las condiciones de alojamiento de los filipinos dentro del recinto de la exposición, aunque también hemos podido comprobar que fue bastante aceptable el suministro de vestidos y alimentos, circunstancia no demasiado común en otros certámenes europeos contemporáneos. Pero, como decíamos, nuestro interés se centra ahora en el contexto genérico que sustenta los vínculos establecidos entre la administración -las autoridades insulares pero, sobre todo, el Ministerio de Ultramar y más aún la Comisaría Regia del certamen-y los filipinos.

Lo primero que advertimos en este sentido es que se produjo una clara desviación de los propósitos originales de los organizadores en cuanto a la presencia de población filipina en el evento de Madrid. La idea primera era que los individuos participantes habrían de desempeñar tareas eminentemente prácticas, aunque también se propuso que tendrían que ostentar cierta representatividad cultural con respecto al resto de los miembros de sus comunidades étnicas o lingüísticas. Aunque no se indicaba de modo explícito, quedaba abierta la puerta a una exhibición puramente visual y exotista, sin cometidos prácticos a desempeñar, de parte de los invitados, siendo el mero espectáculo de sus cuerpos y de sus gestos cotidianos o rituales el principal atractivo de su participación. Esto es efectivamente lo que ocurre con igorrotes y moros, aunque desconocemos si su presencia se debe a la iniciativa del arzobispo de Manila ${ }^{9} \mathrm{o}$ a la de la administración colonial.

${ }^{9}$ El arzobispo de Manila, el dominico Fr. Pedro Payo, fue el principal responsable de las tareas llevadas a cabo en Filipinas para la organización de la exposición. 
Esta exhibición de "salvajes" dio lugar a interesadas conclusiones por parte de ciertos estamentos y grupos de presión peninsulares e insulares, tanto religiosos como civiles, y tanto conservadores como liberales, quienes argumentaron que tal "salvajismo" demostraba el atraso en que aún se encontraba la sociedad filipina. Pero aunque se produce tal coyuntura, y a pesar del dramático acontecimiento de la muerte de tres miembros de la colonia y de las críticas de los ilustrados ${ }^{10}$ y de parte de la prensa por el hecho en sí de la "exhibición" de seres humanos, debemos admitir que la administración española hizo notables esfuerzos para conducir la exposición, y sobre todo la participación de los filipinos, por cauces relativamente dignos y éticamente aceptables. Al menos sobre el papel, todos ellos son "invitados" a participar en el certamen y reciben puntualmente sus gratificaciones - cosa que no ocurre en otros contemporáneos (Rydell 2002: 215)_, asumiéndose en todo momento la capacidad de cada individuo para decidir sobre aquellas cuestiones de índole personal que puedan afectar a sus relaciones con visitantes, estudiosos, autoridades, etc., siempre que no vayan en contra de unas normas básicas de convivencia preestablecidas. Eso no es obstáculo para que se celebren bailes o se organicen visitas que seguramente no fueron del agrado, por lo reiterado, de los filipinos, sobre todo de los igorrotes.

Una cuestión más a destacar es que veintiún filipinos, casi la mitad de la colonia invitada oficialmente por los organizadores, permanece únicamente mes y medio en la Península, ya que parten para Filipinas a finales de julio de 1887; el resto sale de Madrid hacia Barcelona el 19 de octubre, cuatro días después de la clausura oficial y mientras la exposición no ha cerrado aún sus puertas. Esto demuestra que la administración española cumple con lo que suponemos habrían sido sus compromisos con la colonia, sin que en ningún momento exista la intención de "exhibir" a los filipinos al margen de la exposición. Muy diferente es lo que sucede en la misma época en otros contextos expositivos coloniales o lúdico-comerciales, cuyos protagonistas, los nativos, sólo pueden regresar a sus lugares de origen si consiguen evitar los continuos embates de La Parca, tras largos años — diez, doce o más- de interminables y agotadoras "giras" (Blanchard, Bancel y Lemaire 2002: 66).

Pero aún hemos de anotar otros hechos significativos que, si bien algunos pudieran considerarse anecdóticos, revelan de forma clarísima la distancia que separa la muestra de Madrid de otras contemporáneas y nos informan sobre las diferentes ideologías que sustentan los modelos coloniales nacionales e incluso sobre las actitudes igualmente dispares de los

${ }^{10}$ Los ilustrados son los miembros de las élites indígenas y mestizas filipinas educados según cánones occidentales. 
contextos sociales en los que se presentan. Así, en las exposiciones universales belgas, además de articularse perversos y manipulados mensajes coloniales, hubo graves problemas para dar sepultura a los numerosos congoleños fallecidos, sobre todo en el certamen de Bruselas-Tervuren de 1897, pues los vecinos de las poblaciones cercanas se negaron tajantemente a acoger en sus camposantos a los "negros paganos" (Jacquemin 2002: 255). En Madrid no se produjo nada semejante, y se pudo enterrar sin oposición alguna, tanto a los carolinos presuntamente católicos, como a la joloana de religión musulmana. Otro ejemplo: en Madrid no se exhibe ni a niños — salvo el singular caso del joven negrito, quizás adolescente, Tek, que da muestras de una personalidad bastante independiente- ni a familias, aunque sí nos encontramos con parejas, se trate o no de matrimonios. Aparte de las moras, que están acompañadas por varones, no se presenta a ninguna mujer de forma individualizada como objeto de atracción erótica, aunque es cierto que los igorrotes, con sus torsos desnudos, ejercen una más que notable seducción entre el público femenino que asiste al certamen. Tampoco hay desfiles de nativos en el Retiro - aunque sí "danzas de sacrificios" y demostraciones de tiro con arco o lanza-, que son propios de casi todas las exposiciones coloniales contemporáneas, muy especialmente de las norteamericanas y de las francesas (Hale 2002).

Una circunstancia más que singulariza a la madrileña, ahora comparándola directamente con la de Amsterdam de 1883, es la que se vincula con los actos de recepción organizados por las familias reales de ambas monarquías. En Amsterdam, se prometió a los nativos de Surinam llevados al certamen que serían recibidos en palacio por el rey Guillermo III, pero la ceremonia nunca tuvo lugar, aunque parece que el monarca sí visitó en la exposición a los restantes "invitados", a los llegados desde las Indias Orientales ${ }^{11}$. En Madrid, sin embargo, la reina regente María Cristina prodiga tanto las visitas a la exposición como las recepciones en palacio, y en otras dependencias reales, a todos los miembros de la colonia filipina (figura 1). El hecho podría considerarse de escasa relevancia o ser catalogado como una muestra más de paternalismo monárquico, que en modo alguno tendría ninguna otra connotación política o social. Pero, aunque esto sea en parte cierto, no podemos dejar de reconocer que la mera celebración de las recepciones supone un mínimo reconocimiento a la condición humana y a la propia ciudadanía de los "invitados". En realidad, ese evidente paternalismo está presente en casi todos los rincones del modelo colonial español y en la propia exposición de 1887, y es ésta precisamente la circunstancia que hace posible no sólo las recepciones

${ }^{11}$ Agradezco esta información a Peter Mason. 
en palacio, sino los demás actos públicos a los que son invitados todos los filipinos, incluidos los igorrotes, algo que no ocurre en otras muestras contemporáneas.

Estamos terminando; pero, antes, veamos un antepenúltimo detalle que individualiza al evento madrileño. De entre los más de dos centenares de fotografías y grabados disponibles sobre la Exposición de Filipinas, de diferente autoría, ni una sola de las imágenes conocidas reproduce lo que podemos considerar como uno de los más destacados recursos expresivos empleados por empresarios y administradores para dejar constancia de las diferencias existentes entre colonizadores y colonizados, de la subordinación e inferioridad de éstos respecto de aquéllos. Nos referimos a la típica y tópica fotografía que muestra a un grupo de nativos acompañados, dominados, por el citado empresario o responsable blanco: los primeros se exhiben prácticamente desnudos y en actitudes casi siempre sumisas o grotescas; el hombre blanco, por el contrario, aparece erguido, orgulloso e impecablemente vestido. Vemos esta imagen repetida hasta la saciedad en todas las muestras - universales, coloniales o comerciales- celebradas en Europa y América, sin que tampoco sean raras otras en las que, con el mismo propósito de resaltar la tremenda distancia que nos separa de "ellos", los nativos comparten el escenario fotográfico con algún que otro miembro del público que contempla el evento, aunque "compartir"

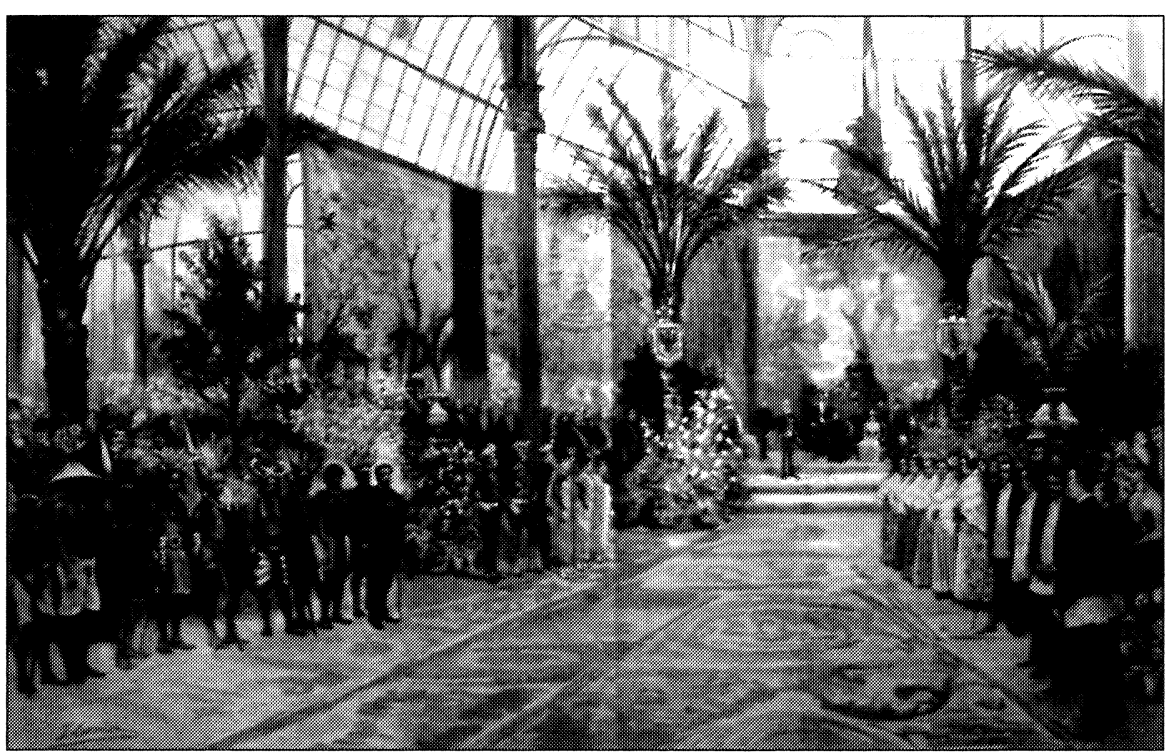

FIgURA 1.-Inauguración oficial de la Exposición de Filipinas por la reina regente María Cristina, el 30 de junio de 1887. La Ilustración Española y América, 8 de julio de 1887. 
no sería precisamente el verbo más adecuado para expresarlo, dado el nulo equilibrio del que participa el mecanismo que lo hace posible.

En Madrid nunca podría haberse tomado tal fotografía, pues de hecho no existe ningún responsable único, directo y exclusivo del evento; es la administración, el Estado, en definitiva, quien lo organiza. Por ello, la única imagen que muestra a un tiempo a colonizadores y colonizados es la litografía reproducida en La Ilustración Española y Americana, el 8 de julio de 1887, que recoge el acto de inauguración del certamen y, aunque expresa de modo tajante y compartimentado la diversidad étnica del Archipiélago, entendida como desigualdad racial, no reproduce los esquemas de subordinación antes citados. Es precisamente ese afán por mostrar a cada grupo étnico de forma diferenciada lo que singulariza el despliegue gráfico del evento de 1887, tanto en las imágenes de J. Laurent y Cía., como en las de Fernando Debas o en las del marqués de Berges ${ }^{12}$. Claro que esto tampoco es una prueba de que se trate sin más de una aproximación esencialmente racista a esa diversidad étnica filipina, pues las fotografías disponibles - tomadas tanto en estudio como en el Retiro- no delatan una intencionalidad antropométrica sino artística y no son muy diferentes de las muy extendidas durante aquellos años que reproducen tipos populares españoles, en las cuales el rasgo a destacar no es la singularidad étnica de los individuos retratados sino, quizás, su carácter rural y arcaizante. Ciertamente, esta circunstancia hace rebotar nuestro argumento, ya que acerca parcialmente a dichos personajes a la condición propia de los nativos de las colonias y viceversa, pues ambos compartirían similares rasgos de arcaísmo y un modo de vida "atrasado".

Es significativo, no obstante, que la única fotografía en la que comparten, ahora sí, el espacio escénico todos los nativos exhibidos, tanto igorrotes como cristianos - faltan los musulmanes, que ya habían abandonado la ciudad-, sea precisamente la que nos los presenta, tras haber recibido una modesta condecoración oficial, adecuadamente vestidos: los cristianos con su indumentaria habitual y los igorrotes con sencillos aunque correctos ropajes proporcionados por los organizadores. $\mathrm{Y}$ un dato más: todos ellos posan sobre la escalinata de acceso al Pabellón Central, el edificio principal de la muestra que hoy conocemos como Palacio de Velázquez, en un escenario "civilizado" que podía haber compartido gus-

${ }^{12}$ En el Archivo Ruiz-Vernacci, del Ministerio de Cultura, se conservan 22 placas de cristal originales de las 45 que J. Laurent y Cía. tomó de la exposición; un álbum con todas las imágenes se encuentra en el Archivo de Palacio. Copias de las fotografías de Debas se guardan en el Museo Nacional de Antropología y un álbum con las tomas del marqués de Berges se puede consultar en la Biblioteca Museu Víctor Balaguer, en Vilanova i la Geltrú. 
toso cualquier occidental, aunque ni siquiera ahora se introduce este último elemento en la imagen (figura 2). Los nativos se muestran así con una personalidad propia y digna de respeto. Es cierto, y vuelven a rebotar nuestros argumentos, que también podríamos considerar que ese despliegue de imágenes se hace de forma excesivamente rígida e individualizada, manifestando así de modo implícito que la esencia humana de esas gentes es casi por completo ajena a la esencia occidental. Es ésta una interpretación que, sin embargo, no acabamos de compartir, aunque aceptamos que sea parcialmente asumible.

Pasemos ahora al penúltimo asunto, también vinculado con las representaciones gráficas de la exposición de 1887. Hemos apuntado que no conocemos imagen alguna que presente al hombre blanco "dueño" de los nativos, y es cierto. Pero sí existen dos fotografías en las que se muestra, junto con los indígenas exhibidos, a un singular personaje que asume de forma parcial e incompleta aquella condición. Nos referimos a los clichés en los que aparece el tinguián Ismael Alzate, un igorrote perfectamente aculturado y entusiasta colaborador de la administración española que se encargó oficialmente de la supervisión y el control de toda

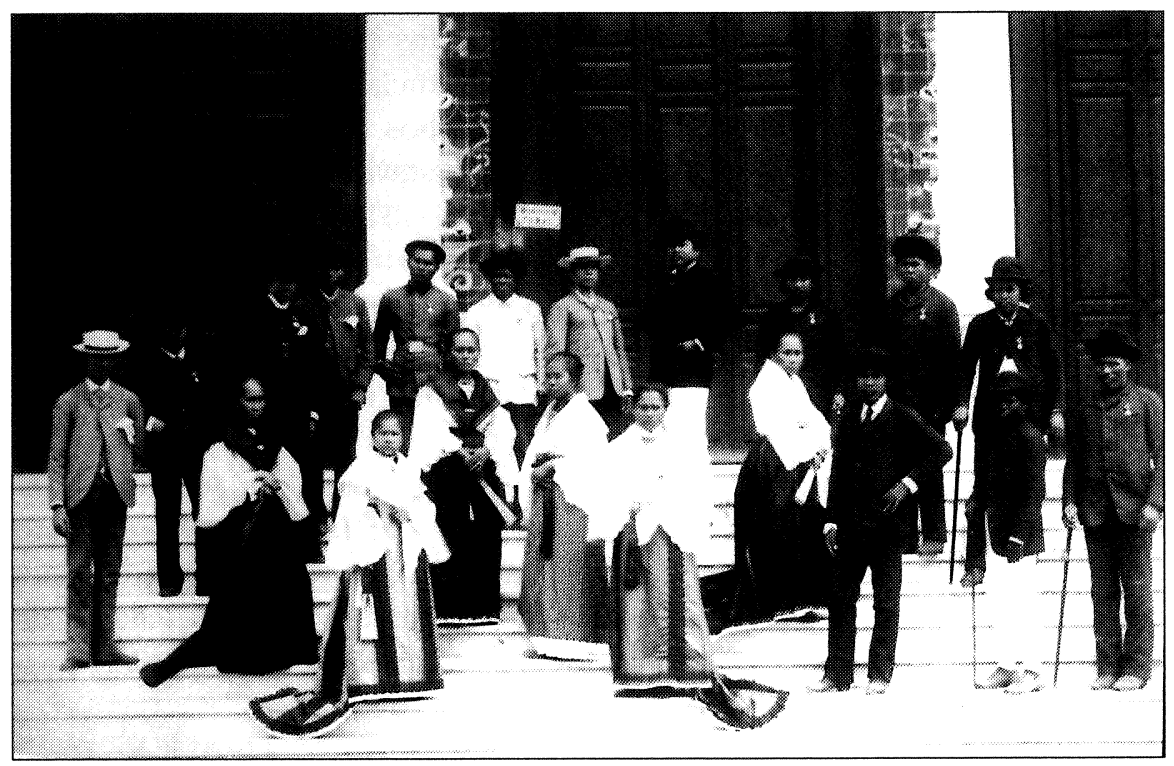

Figura 2.-Parte de la colonia filipina llegada a Madrid posa sobre la escalinata de acceso al Pabellón Central de la exposición (actual Palacio de Velázquez) tras recibir una medalla conmemorativa. En el nivel superior, con pantalón blanco y bombín, se sitúa Ismael Alzate. Archivo fotográfico del Museo Nacional de Antropología, sede de la calle de Alfonso XII. 
la colonia filipina llegada a la Península, y en especial de igorrotes y moros. Una de las fotografías es la ya citada en la que se ve a algunos de los filipinos, incluidos los igorrotes, posando en las escalinatas del Pabellón Central. Aquí, Alzate se presenta casi como un miembro más del grupo; observándola, en modo alguno se puede deducir que tuviera ninguna responsabilidad especial sobre sus compañeros, al margen de que ciertamente no formara parte en sentido estricto del estamento organizador. Lo único que se permite este personaje es posar casi en el centro del grupo y un escalón por encima de los demás filipinos; eso sí, su porte resulta decididamente altanero.

La segunda fotografía es una imagen de estudio, obra de Fernando Debas, que muestra a los igorrotes en pie, con su escueta indumentaria habitual y, frente a ellos, a Alzate, quien aparece recostado, con abandono y marcado aire chulesco y socarrón, sobre la rodilla de uno de los "salvajes" —el único que se encuentra sentado-, vistiendo elegante levita sobre la que pende la condecoración recibida, mientras sujeta con despreocupación una lanza que cruza oblicuamente sobre su cuerpo con el propósito de equilibrar la composición ${ }^{13}$ (figura 3). Desde luego, nada tienen que ver ambas imágenes con las del empresario blanco dominador. Aquí, es la figura de Alzate, un nativo, la que recibe todos los honores, como una re-

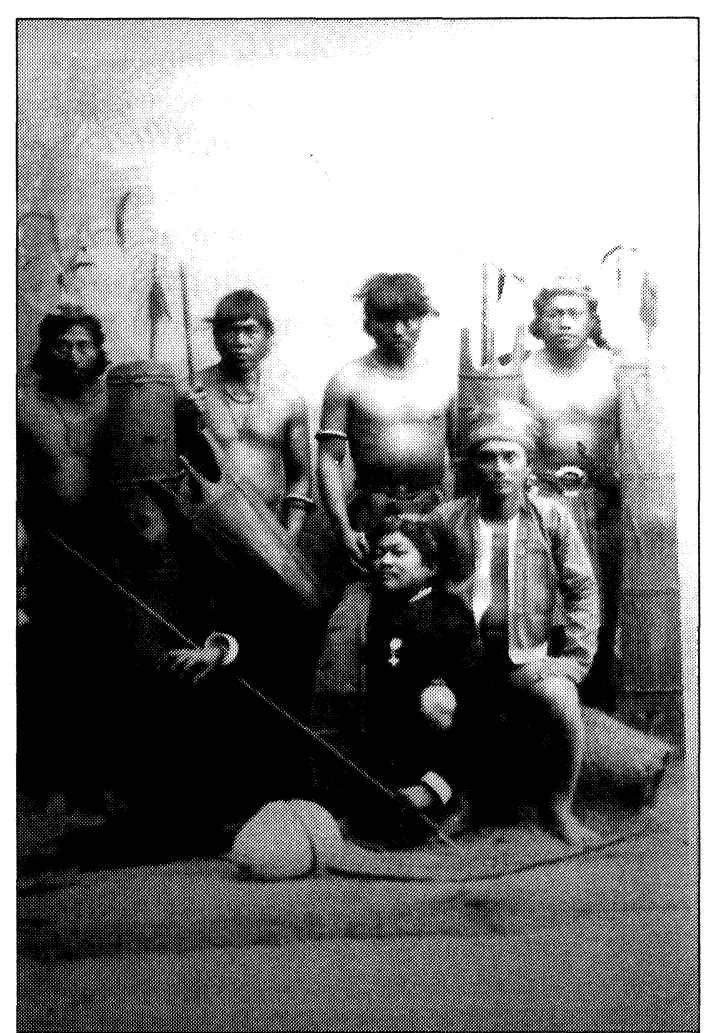

FIGURA 3.-Fotografía de estudio de Ismael Alzate y varios igorrotes, tomada por Fernando Debas. Archivo fotográfico del Museo Nacional de Antopología sede de la calle de Alfonso XII.

\footnotetext{
${ }^{13}$ Las dos fotografias citadas se conservan en el Museo Nacional de Antropología, en su sede de la calle de Alfonso XII.
} 
compensa más a su colaboración con la "madre patria". Si la primera de las dos fotografías le muestra compartiendo, y parcialmente dominando, un territorio marcadamente occidental entre el resto de sus compatriotas, en la segunda se deja clara constancia de su absoluto y cómodo control sobre el "lado salvaje" de la colonia, sobre sus convecinos que aún no participan de las bendiciones de la civilización. Por último, también podríamos considerar ambas imágenes como un homenaje de la administración española a su propia labor colonial, y en concreto a su exitosa capacidad, manifestada desde los primeros momentos de la conquista, para obtener el apoyo de las élites indígenas en el proceso colonizador.

Concluyendo ya, ahora sí, nuestra valoración del certamen de 1887, deseamos llamar la atención sobre una última cuestión, sobre la voluntariedad de la presencia de los filipinos en la exposición. Aunque carecemos de noticias precisas al respecto, podemos afirmar con casi total seguridad que ni se recurrió al secuestro ni parece que esas personas fueran forzadas a participar, prácticas éstas que eran empleadas desde tiempo atrás, e incluso durante esos mismos años de finales del XIX, con indígenas mostrados en otros lugares de Europa. Lo que no podemos saber es si efectivamente todos los filipinos fueron conscientes, antes de abandonar el Archipiélago, de las consecuencias que se podrían derivar del largo viaje y de su estancia en la "madre patria". En este sentido, no parece que el negrito Tek, todo un adolescente o casi, tuviera una idea ni siquiera aproximada del tremendo enredo en el que se iba a involucrar al embarcarse en Manila rumbo a Barcelona. $\mathrm{Y}$ eso que todo apunta, por las informaciones de prensa de la época, a que incluso pudo disfrutar, en cierto sentido, de su estancia en la Península. En cuanto a los igorrotes, tuvieran o no plena conciencia de lo que implicaba el traslado, parece que participaron gustosos en el certamen, animados por la esperanza de obtener determinados beneficios, tanto económicos como de prestigio social. Algo similar hubo de ocurrir con los restantes filipinos, incluidos quizás también los moros y moras de Joló y Mindanao.

Si aceptásemos —como proponen Bancel, Blanchard y Lemaire (2000)— que la brutalidad de las exhibiciones no hace sino reproducir la propia crueldad de la conquista colonial, animalizando a las poblaciones conquistadas, habríamos de concluir que en el caso filipino la brutalidad de los españoles fue mucho menos intensa que la vivida en otros territorios coloniales y que de algún modo esto quedó reflejado en la exhibición de 1887. No obstante, aunque en nuestro caso las circunstancias parece que fueron precisamente éstas, tal planteamiento no resulta del todo sostenible, pues existen disparidades notables entre determinados sistemas coloniales y su proyección en el ámbito exhibidor, como hemos anotado para 
el caso belga, al margen de que los autores mencionados no establecen con total claridad las diferencias existentes entre las exposiciones coloniales oficiales y las exhibiciones exotistas privadas, que pueden celebrarse, tanto de forma independiente, como integradas en exposiciones universales.

En realidad, la representación expositiva de las gentes y los territorios colonizados casi nunca se propone asentar modelos explícitos de explotación y subordinación basados en la fuerza; se suele optar por mecanismos mucho más sutiles de dominación, articulados a través de unos muy humanos y respetables propósitos de cristianización y civilización. Lo que sí es cierto es que las distintas ideologías coloniales tienen, efectivamente, un reflejo directo en cada uno de los certámenes, como ocurre con el de Madrid en 1887.

En este sentido, el rasgo más destacado de esa exposición es, pese a su muy exitosa parcela "salvajística", el verdadero empeño que pone la administración en evitar la presentación de Filipinas como una simple colonia. No es, por tanto, la imagen de una Filipinas colonial la que se quiere hacer pública en Madrid, sino la de un territorio español de ultramar más o menos exótico y salvaje. Quizás sea este obsesivo, aunque irreal, modelo ideal de "colonialismo hispánico no colonialista" la circunstancia que precisamente explique la incapacidad o la falta de voluntad para articular una etnología colonial oficial. Pese a todo, a nadie escapa, ni antes ni después de 1887, que el archipiélago filipino es una colonia y que lo que aquel año se muestra en el Parque del Retiro es precisamente un territorio colonizado, aunque aún sea de forma incompleta, por España; un territorio habitado por gentes que muchos consideran inferiores $\mathrm{o}$ infantiles, lo que no es obstáculo para que se vislumbre un brillante futuro económico insular que habría de beneficiar igualmente a la metrópoli, razón ésta que es precisamente una de las principales que mueven a la celebración del evento.

En definitiva, la exposición se nos muestra como un nítido reflejo de la inestable y contradictoria estructura de las relaciones coloniales hispano-filipinas ${ }^{14}$, que insiste en manifestar la condición de territorio español de ultramar, de una provincia más, del Archipiélago, pero ni le aplica la legislación general vigente en la Península ni garantiza las libertades públicas de sus ciudadanos, además de no reconocer sus espectaculares progresos. Al mismo tiempo, el modelo manifiesta claramente en la prác-

${ }^{14}$ El carácter ambivalente y contradictorio del modelo de relaciones coloniales no es exclusivo del caso español, pese a sus singularidades. Desde la teoría postcolonial se insiste precisamente en considerar tal circunstancia como uno de los rasgos caracterizadores de cualquier estructura de dominio colonial (Gandhi, 1998:11). 
tica la condición de colonia, de colonia de la Corona, de Filipinas, pero no se elaboran leyes especiales para su gobierno ni se consolida un modelo de explotación económica sustentado en la iniciativa privada; las órdenes religiosas, el ejército y una administración insular obsoleta, despótica y en buena medida racialista - pese al relamido discurso asimilacionista de la administración peninsular - controlan hasta el último momento los resortes de la maquinaria colonial.

Insistimos, finalmente, en que la nueva imagen del colonialismo español en Filipinas durante el último tercio del XIX es mucho más una imagen y un deseo, más o menos compartido, que una realidad, aunque los cambios que se introducen en ciertos sectores de la administración colonial sean ciertamente significativos. Por ello, y a pesar de que podemos asumir que todos los procesos coloniales, y especialmente los conducidos por las potencias europeas durante la segunda mitad del siglo XIX, comparten unas muy básicas y elementales estructuras de dominación y reinterpretación simbólica y práctica de las comunidades subyugadas, consideramos que la especificidad y singularidad del modelo colonial español articulado en el espacio filipino quedó patente en 1887. Para bien o para mal, tanto de colonizadores como de colonizados, España era diferente ${ }^{15}$.

Y si de la valoración colonial pasamos a la estrictamente expositiva, hemos de concluir que, si bien el certamen de 1887 se inspira en el de Amsterdam en la guía o propuesta de ámbitos y elementos a presentar en una muestra pública de la sociedad colonial —incluida la presencia de población indígena-, se aleja radicalmente de aquél, y de otras exposiciones contemporáneas, en la concepción ideológica que sustenta el despliegue exhibidor. Es evidente que lo que en los Países Bajos se coloca $-\mathrm{y}$ nos referimos al certamen en su conjunto- en compartimentos prácticamente estancos, en una estructura marcadamente vertical del espacio simbólico y práctico colonial, en España se articula de forma horizontal y abierta, aunque más bien habríamos de calificarla de "pseudointerétnica", dados los problemas y circunstancias negativas a las que hemos ido haciendo mención a lo largo de nuestro estudio. Además, la evidente brutalidad que se documenta en exhibiciones similares, vistas en otros países europeos durante aquellos mismos años, está casi por completo ausente en la de Madrid, sin que esta afirmación suponga des-

15 Podemos aceptar, como defienden durante los últimos años algunos historiadores españoles y extranjeros, que la historia de España no ha sido tan extraña y singular como algunos pretenden, pero esto no es obstáculo para reconocer que las diferencias en los procesos históricos existen y pueden resultar muy significativas. 
deñar en modo alguno las tremendamente negativas circunstancias que se asocian a la exhibición de seres humanos, en cuanto que seres singulares que se muestran a sí mismos y no algún tipo de habilidad o cualidad, y el aún más dramático y gratuito fallecimiento de tres de las personas llegadas a tierras españolas.

De alguna forma, y aunque el modelo colonial español conduce a muy notables singularidades, la exposición del 87 se adelanta - por su carácter pretendidamente asimilacionista y su afán por presentar más a indígenas" y a nativos en proceso de civilización que a simples "salvajes", aunque éstos no falten - a las que se van a contemplar en Europa, sobre todo en Francia y Gran Bretaña, algunos años después, como ocurre en cierta medida en Marsella (1906 y 1922), Wembley (1924-25), ParísVincennes (1931) o Glasgow (1938); pero ésta es una anotación que hacemos con todas las reservas, dado que deberíamos estudiar con detalle todos los certámenes mencionados. En conclusión, si las exposiciones universales y coloniales tan en boga, tan agotadoramente en boga, durante aquellos años sirvieron de marco general de referencia a la muestra de 1887 y si la de Amsterdam de 1883 resultó el más interesante modelo a imitar, a pesar de las distancias, el resultado final del evento madrileño no podía haber sido más diferente al del neerlandés y a los de la inmensa mayoría, o quizás la totalidad, de las exhibiciones coloniales contemporáneas.

\section{BIBLIOGRAFÍA CITADA}

Afable, Patricia O. 1998. “Eduardo Masferré's subjects: a century of self-representation in the Philippines". Anales del Museo Nacional de Antropologia V: 83-107.

Bancel, N., P. Blanchard y S. Lemaire. 2000. "Ces zoos humains de la République coloniale. Des exhibitions racistes qui fascinaient les européens". Le Monde Diplomatique agosto 2000: 16-17 [ed. electrónica, http://www.monde-diplomatique.fr/ 2000/08/BANCEL/14145].

BANCEL, N. et al. (dirs.). 2002. Zoos humains. XIX et $X X^{e}$ siècles. París: Édítions La Decouverte.

Belle Europe. 2001. La Belle Europe: le temps des expositions universelles. 1851-1913. Musées Royaux d'Art et D'Histoire, Bruxelles. Du 26 octobre 2001 au 17 mars 2002. Bruselas: Tempora.

BENEDiCT, BuRTON. 1983. The anthropology of world's fairs: San Francisco's Panama Pacific International Exposition of 1915. Berkeley, Londres: Lowie Museum of Anthropology, Scholar Press.

- 1994 "Rituals of representation: ethnic stereotypes and colonized peoples at world's fairs", en R. W. Rydell y N. E. Gwinn (eds.), Fair representations: world's fairs and the modern world: 28-61. Amsterdam: VU University Press. 
Blanchard, P., N. BANCEL Y S. LEMAIRE. 2002. "Les zoos humains: le passage d'un 'racisme scientifique' vers un 'racisme populaire et colonial' en Occident", en N. Bancel et al. (dirs.), Zoos bumains. XIX $X^{e}$ et $X X^{e}$ siècles: 63-70. París: Éditions La Decouverte.

BODGAN, ROBERT. 1988. Freak show: presenting buman oddities for amusement and profit. Chicago, Londres: The University of Chicago Press.

CABrera LATORre, Ángel. 1900. "Esquimales del Buen Retiro". Actas de la Sociedad Española de Historia Natural XXIX: 184-188.

Calvo TeIXeIra, Luis. 1992. Exposiciones Universales: el mundo en Sevilla. Barcelona: Ed. Labor, RTVE, Sociedad Estatal para la Exposición Universal Sevilla 92, S. A.

CONTRERAS, JeSús E IGNASI TERRADES. 1984. "L'exhibició d'aixantis a Barcelona, l'any 1897n. L'Avenç 72: 30-36.

CORBEY, RAIMOND. 1993. "Ethnographic Showcases, 1870-1930". Cultural Anthropology 8 (3): 338-369.

COUTANCIER, BENOÎT. (ed.). 1992. "Exhibitions ethnographiques et vulgarisation scientifique (1877-1890)", en B. Coutancier (dir.), "Peaux-Rouges»: autour de la collection antbropologique du prince Roland Bonaparte: 34-37. París: Éditions de l'Albaron, Photothèque du Musée de l'Homme, Museum National d'Histoire Naturelle.

EXPOSICIÓn COLONIAL. 1882. Exposición Colonial de Amsterdam. Subcomisión de Filipinas. Manila: Imp. de "La Oceanía Española".

FEEST, CHRISTIAN F. (ed.). 1987. Indians and Europe: an interdisciplinary collection of essays. Aachen: Editions Herodot, Rader Verlag.

FINDLING, JOHN E. (ed.). 1990. Historical dictionary of world's fairs and expositions, 1851-1988. New York, Westport, Londres: Greenwood Press.

GANDHI, LEELA. 1998. Postcolonial theory: a critical introduction. Edimburgo: Edinburgh University Press.

GREENHALGH, PAUL. 1988. Ephemeral vistas: the expositions universelles, great exhibitions and world's fairs, 1851-1939. Manchester: Manchester University Press.

HALE, DANA S. 2002. "L"indigene' mis en scène en France, entre exposition et exhibition (1880-1931)", en N. Bancel et al. (dirs.), Zoos bumains. XIX $X^{e}$ et XX siècles: 315-322. París: Éditions La Decouverte.

HOCHSCHILD, ADAM. 2002. El fantasma del rey Leopoldo: una bistoria de codicia, terror $y$ beroísmo en el África colonial. Barcelona: Ediciones Península.

JACQUEMIN, JEAN-PIERRE. 2002. "Les Congolais dans la Belgique 'impériale'”, en N. Bancel et al. (dirs.), Zoos bumains. XIX et XX $X^{e}$ siècles: 253-259. París: Éditions La Decouverte.

MASON, PETER. 1998a. Infelicities: representations of the exotic. Baltimore, Londres: The Johns Hopkins University Press.

- 1998b. "No show", en E. van Dongen y S. van Londen (eds.), Antbropology of difference: essays in bonour of Professor Arie de Ruijter: 139-157. Utrecht: ISOR..

- 2001. "The lives (and deaths) of Fuegians and their images", en P. Mason, The live of images. Londres: Reaktion Books.

PLUM, WERNER. 1977. Exposiciones mundiales en el siglo XIX: espectáculos del cambio socio-cultural. Bonn: Friedrich-Ebert-Stiftung.

RYDELL, ROBERT W. 1984. All the world's a fair: visions of empire at American international expositions, 1876-1916. Chicago: University of Chicago Press.

- (introd.). 1992. The books of the fairs: materials about world's fairs, 1834-1916, in the Smithsonian Institution Libraries. Chicago: American Library Association.

- 1993. World of fairs: the century-of-progress expositions. Chicago, Londres: The University of Chicago Press. 
- 2002. "Africains en Amérique: les villages africains dans les expositions internationales américaines (1893-1901)", en N. Bancel et al. (dirs.), Zoos humains. XIX et XX $X^{e}$ siècles: 213-220. París: Éditions La Decouverte.

RYdell, R. W.; J. E. Findling Y K. D. Pelle. 2000. Fair America: world's fairs in the United States. Washington D. C.: Smithsonian Institution Press.

RYDELL, ROBERT W. Y NANCY E. GWINN. (eds.). 1994. Fair representations: world's fairs and the modern world. Amsterdam: VU University Press.

SCOTT, WilliaM H. 1988. "Introduction", en Fr. F. Antolín, O.P., Notices of the pagan igorots in the interior of the Island of Manila: xii-xvi. Manila: UST Press.

TenKotTe, Paul A. 1987. "Kaleidoscopies of the world: international exhibitions and the concept of culture-place", 1851-1915". American Studies 28: 5-29.

VERDE CASANOVA, ANA. 1993. "Fotografía y antropología: inuit en Madrid, 1900". Anales del Museo de América 1: 85-98.

- 1994. "Una página en la historia de los inuit de Labrador: 'esquimales del Polo al Retiro'.. Revista Española de Antropología Americana 24: 209-229. 